\title{
Modificação do Acetato de Celulose em Meio Homogêneo Via Reações de Condensação com Diferentes Isocianatos.
}

\author{
Vagner R. Botaro e Alessandro Gandini
}

Resumo: Este estudo descreve uma série de reações envolvendo os grupos isocianatos $(N C O)$ e os grupos hidroxílicos do acetato de celulose com grau de substituição $(D S)$ igual a 2,4. As reações foram realizadas em meio homogêneo e utilizaram dois isocianatos estruturalmente diferentes: o 3-isopropenil- $\alpha, \alpha$ '-dimetilbenzil isocianato (TMI) e o 2-isocianato-etil metacrilato (IEM). Um acompanhamento cinético das reações foi realizado por espectroscopia na região do infravermelho, onde acompanhou-se o desaparecimento da banda típica de isocianato a aproximadamente $2260 \mathrm{~cm}^{-1}$. Filmes de acetato de celulose modificados foram obtidos após as reações, sendo posteriormente caracterizados por análises de ângulos de contato, espectroscopia na região do infravermelho e ensaios de tração.

Palavras-chave: Acetato de celulose, isocianatos, reações de modificação, uretanas, cinética, propriedades de superfície, tração.

\section{Introdução}

A natureza tem a propriedade de ser uma fonte verdadeiramente inesgotável de vários tipos de compostos, incluindo as pequenas moléculas, os oligômeros e finalmente as macromoléculas e polímeros naturais ${ }^{[1,2]}$. A maior parte desses compostos possuem estrutura essencialmente orgânica embora não se deva esquecer de alguns compostos organo-metálicos e complexos que são igualmente importantes.

Esses diversos compostos são uma fonte extremamente abundante e podem ser utilizados diretamente como encontrados na natureza ou sofrer algum tipo de modificação química antes de serem utilizados. $\mathrm{Na}$ maioria dos casos essas modificações químicas sobre os produtos naturais originam novos materiais poliméricos com estrutura e propriedades fisico-químicas que diferem da matéria-prima original ${ }^{[3]}$.

$\mathrm{O}$ grande interesse no desenvolvimento de tais materiais está diretamente relacionado ao caráter renovável da grande maioria dos compostos vegetais que têm sua produção garantida simplesmente pela energia solar. Essa característica torna-se ainda mais importante quando colocada diante da futura escassez dos compostos derivados do petróleo que são atualmente empregados na síntese da grande maioria dos polímeros sintéticos.

Em termos numéricos a produção da biomassa vegetal terrestre está estimada em cerca de $3 \times 10^{11}$ 
toneladas por ano ${ }^{[2]}$. Esses valores superam as quantidades de minerais extraídos e mesmo particularmente as reservas de petróleo disponíveis. Esse simples quadro comparativo mostra de forma expressiva o grande potencial apresentado pela biomassa vegetal e que deve sem dúvida ser bastante explorado. Dentro de tal contexto, a derivatização da celulose é particularmente importante e uma série de derivados são preparados a partir de celuloses de diferentes fontes ${ }^{[4,5]}$. Um outro aspecto igualmente importante é a modificação superficial de celuloses em particular e de materiais lignocelulósicos em geral tendo como objetivo principal as suas utilizações na formação de materiais compósitos ${ }^{[6,7]}$. Nesses casos, as fibras modificadas são mais compatíveis quimicamente com as matrizes poliméricas empregadas na formação desses materiais, resultando em um aumento da adesão fibra-matriz ${ }^{[7]}$.

O presente trabalho descreve uma série de reações de modificação do acetato de celulose em meio homogêneo com isocianatos. Dois distintos reagentes foram escolhidos para essa investigação, o 3 -isopropenil- $\alpha, \alpha$ '-dimetilbenzil isocianato $(T M I) \mathrm{e}$ o 2-isocianatoetil metacrilato (IEM). Filmes de acetato de celulose e acetato de celulose modificados foram obtidos e caracterizados por uma série de técnicas experimentais tais como espectroscopia na região do infravermelho (FTIR), medidas de ângulos de contato e ensaios de tração.

\section{Experimental}

\section{Materiais}

Tetraidrofurano ( $T H F$, grau espectral): seco por 48 horas utilizando-se 50 gramas de peneira molecular ( $3 \AA$, ativada em estufa a $110^{\circ} \mathrm{C}$ por 5 horas) por litro de THF.

3-isopropenil- $\alpha, \alpha$ '-dimetilbenzil (TMI, 99\%) e Dibutil-dilaureato de estanho (catalisador, 99\%)Aldrich Chemical Company;

2-isocianatoetil metacrilato (IEM, 99\%) - Fluka Chemical Company.

Acetato de celulose $(A C)$ : Produto comercial contendo um grau de substituição igual a 2,4.

A Figura 1mostra as estruturas químicas dos dois distintos isocianatos empregados nas reações de modificação do acetato de celulose;

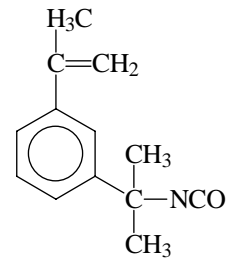

(TMI)<smiles>C=C(C)C(=O)OCCC=O</smiles>

(IEM)
Figura 1. Estruturas químicas dos isocianatos utilizados nas reações de modificação do acetato de celulose.

\section{Equipamentos e técnicas}

\section{Espectroscopia na região do infravermelho}

Essas análises utilizaram um espectrômetro de absorção na região do infravermelho com transformada de Fourier (FTIR) marca Perkin Elmer, Paragon 1000. Uma série de soluções foram preparadas a partir de pequenas amostras retangulares $(0,5 \times 1,0 \mathrm{~cm})$ retiradas dos filmes de acetato de celulose não modificado e filmes modificados. A cada uma das amostras foi adicionado cerca de $1,0 \mathrm{~mL}$ de THF seguindo-se a completa dissolução dos filmes sob agitação magnética. Duas gotas das soluções resultantes foram adicionadas sob pastilhas de $\mathrm{KBr}$ que posteriormente foram secas em estufa à vácuo, transferidas para dessecador e analisadas por FTIR.

\section{Ensaios de Tração}

Esses ensaios empregaram uma máquina de tração INSTRON TI 223-1071 com carga máxima ajustada a $100 \mathrm{~N}$. Os filmes de acetato de celulose e acetato de celulose modificados foram cortados em tiras de aproximadamente $10,0 \mathrm{~cm}$ de comprimento por $1,0 \mathrm{~cm}$ de largura. As espessuras dos filmes foram determinadas e variaram entre 60 a $70 \mu \mathrm{m}$. Durante os ensaios a temperatura e a umidade relativa do ar foram controladas e permaneceram a $25^{\circ} \mathrm{C}$ e $40 \%$ respectivamente. A velocidade de extensão foi de $1,0 \mathrm{~mm} / \mathrm{min}$ sendo que os ensaios utilizaram garras metálicas com ranhuras mantidas a uma distância inicial de $5,0 \mathrm{~cm}$.

\section{Medidas de Ângulos de Contato}

O aparelho para medidas de ângulos de contato entre uma gota de líquido e uma superfície sólida, é constituido basicamente de duas partes distintas in- 


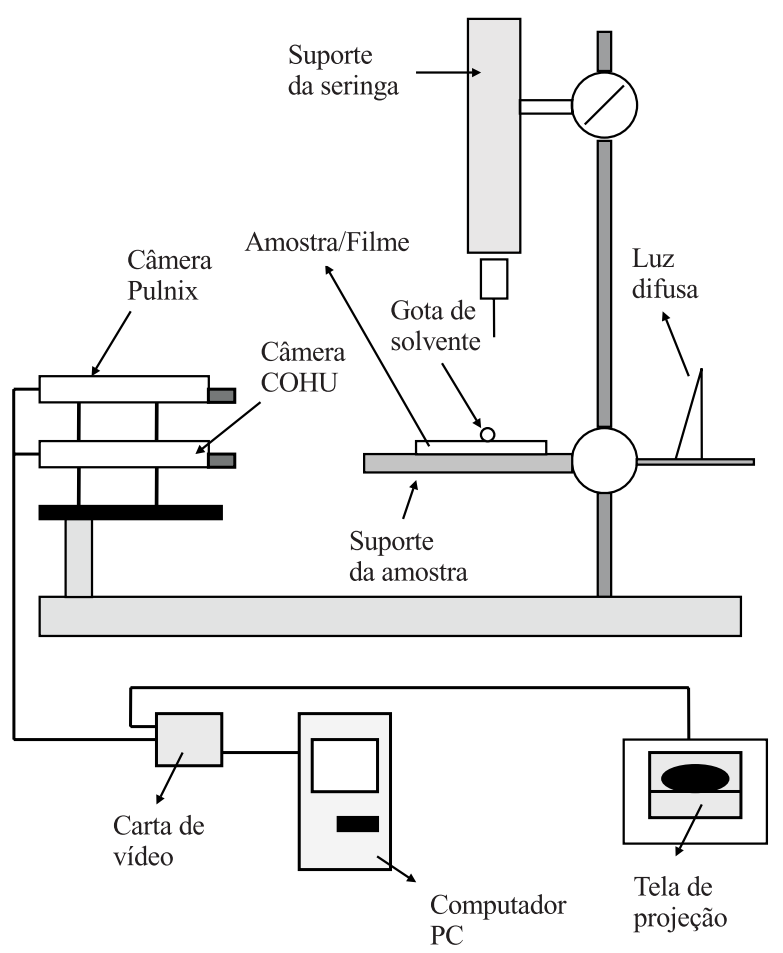

Figura 2. Representação esquemática do aparelho utilizado nas medidas de ângulos de contato ${ }^{[8]}$.

cluindo o sistema ótico e o sistema operacional que são mostrados na figura acima.

A parte ótica é composta de um sistema de processamento de imagens, duas câmeras, um monitor de vídeo e um sistema de iluminação. O sistema de processamento armazena e processa as imagens captadas pelas duas câmeras durante as medidas. Essas duas câmeras de vídeo trabalham a diferentes frequências, $25 \mathrm{~Hz}$ e $250 \mathrm{~Hz}$ sendo que a primeira é especialmente importante para registros de processos que ocorram a velocidades em torno de alguns milisegundos. Dentro da parte ótica deve-se destacar também a importância do sistema de iluminação que emprega uma lâmpada de neon a $30 \mathrm{kHz}$ e que permite obter uma luminosidade homogênea durante a aquisição das imagens.

O sistema operacional é composto de uma seringa de $10 \mu \mathrm{L}$ acoplada a um suporte que permite o seu deslocamento vertical. Um aparato de fixação permite a movimentação das câmeras no sentido horizontal e vertical e assim um melhor ajuste das imagens. Finalmente o sistema operacional apresenta uma plataforma metálica posicionada em frente às câmeras sendo também móvel e ajustável.

Os filmes de acetato e acetatos modificados utilizados nesses ensaios foram cortados em pequenas tiras de aproximadamente $1 \mathrm{~cm}$ de largura por $5 \mathrm{~cm}$ de comprimento e fixas sob a plataforma metálica decrita acima. As determinações de ângulo de contato foram realizadas no mínimo 8 vezes para cada filme a fim de se obter uma média confiável de valores.

\section{Reações de derivatização do acetato de celulose com isocianatos}

Tipicamente, 10,0 gramas de acetato de celulose foram adicionadas no interior de um erlenmeyer juntamente com um volume de $100,0 \mathrm{~mL}$ de THF seco a fim de se preparar uma solução $10 \% \mathrm{~m} / \mathrm{v}$. A mistura foi agitada com auxílio de agitador magnético por 24 horas à temperatura ambiente possibilitando assim a total dissolução do acetato de celulose.

As soluções estoque de isocianato e de catalisador foram preparadas diretamente pela adição de uma massa conhecida do produto em THF a fim de se obter uma solução $10 \% \mathrm{~m} / \mathrm{v}$ e $2 \% \mathrm{~m} / \mathrm{v}$ respectivamente.

Todas as reações foram realizadas sob as mesmas condições de temperatura $\left(25^{\circ} \mathrm{C}\right.$, controlada por um banho termostático) e sob atmosfera de nitrogênio. Cerca de $5 \mathrm{ml}$ da solução acetato $(10 \% \mathrm{~m} / \mathrm{V})$ foi introduzida no interior de um erlenmeyer de $50 \mathrm{~mL}$ de capacidade munido de um septo de borracha. Os volumes finais das reações foram de $40 \mathrm{~mL}$ e as razões molares entre as quantidades de catalisador e isocianato foram constantes e iguais a $0.5 \%$. Finalmente, as quantidades de isocianato foram variáveis como mostradas na tabela 1 .

\section{Formação dos Filmes de Acetato de Celulose Mo- dificados}

Após término das reações, a mistura reacional foi transferida a um refrigerador e mantida a $-5^{0} \mathrm{C}$ por 30 minutos. Essa mistura foi transferida rapidamente a uma placa de Petri $(11,5 \mathrm{~cm}$ de diâmetro interno) e coberta com papel alumínio permanecendo à temperatura controlada de $25^{\circ} \mathrm{C}$ por 48 horas e sob

Tabela 1. Quantidades molares relativas empregadas nas reações de modificação de acetato de celulose com TMI e IEM.

\begin{tabular}{cccc}
\hline $\begin{array}{c}\text { Reações } \\
\text { TMI }\end{array}$ & $\begin{array}{c}\text { Razão } \\
\mathbf{n}_{\mathrm{NCO}} / \mathbf{n}_{\mathrm{OH}}\end{array}$ & $\begin{array}{c}\text { Reações } \\
\text { IEM }\end{array}$ & $\begin{array}{c}\text { Razão } \\
\mathbf{n}_{\mathrm{NCO}} / \mathbf{n}_{\mathrm{OH}}\end{array}$ \\
\hline TMI125 & 0.5 & IEM125 & 0.5 \\
TMI225 & 1.0 & IEM225 & 1.0 \\
TMI325 & 1.5 & IEM325 & 1.5 \\
TMI425 & 2.5 & IEM425 & 2.5 \\
\hline
\end{tabular}


uma superfície extremamente plana. Os filmes assim formados foram retirados cuidadosamente da placa $\mathrm{e}$ extraídos por 48 horas com etanol utilizando-se um sistema de soxhlet. Em seguida os filmes foram transferidos a um dessecador com sílica e sob vácuo. Um filme de acetato de celulose não modificado (filme padrão) foi formado utilizando-se $5,0 \mathrm{~mL}$ de solução de acetato $10 \% \mathrm{~m} / \mathrm{v}$ e a metodologia descrita acima.

\section{Acompanhamento Cinético das Reações}

As reações de modificação foram acompanhadas cinéticamente por espectroscopia na região do infravermelho sendo que a metodologia inclui a utilização de uma cela normalmente empregada para registrar espectros de infravermelho de líquidos. Com o auxílio de uma seringa de vidro foram coletados cerca de $0,5 \mathrm{~mL}$ do interior da mistura reacional e introduzidos rapidamente no interior da cela. Acompanhou-se o desaparecimento da banda de estiramento $\mathrm{CN}$ a aproximadamente $2200 \mathrm{~cm}^{-1}$ durante o intervalo das reações. Tal procedimento foi também utilizado para o caso das reações-padrão entre os isocianatos com água e/ou metanol.

\section{Resultados e Discussão}

Acompanhamento Cinético das Reações por Espectroscopia na Região do Infravermelho

A Figura 3 abaixo mostra uma ampliação da região do espectro de FTIR e um exemplo do acompa-

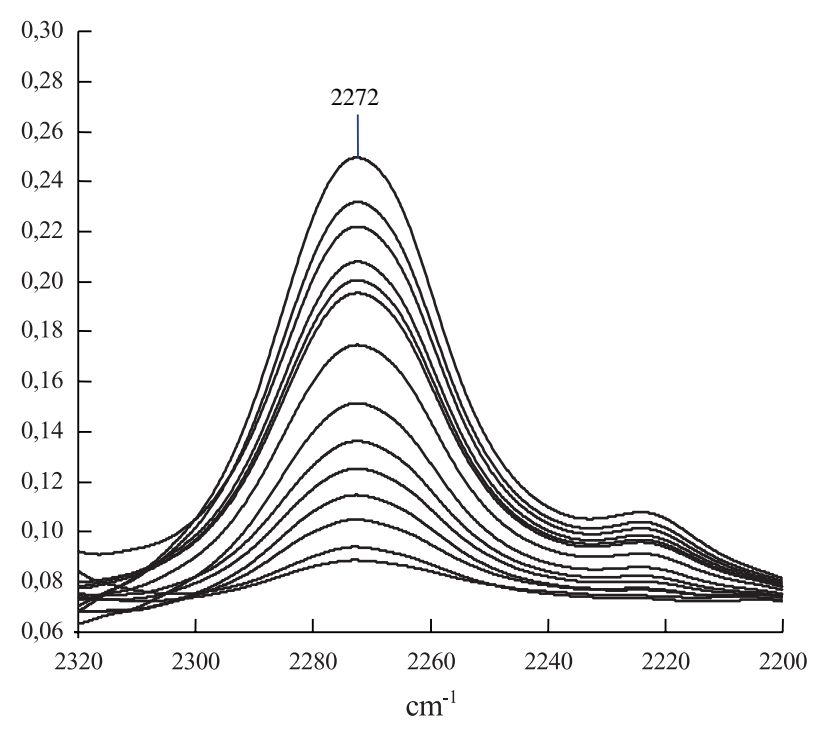

Figura 3. Acompanhamento cinético de uma reação típica entre acetato de celulose e TMI pelo desaparecimento da banda de $\mathrm{CN}$ do isocianato. nhamento cinético das reações envolvendo o acetato de celulose e os isocianatos. Nessa figura pode-se observar o desaparecimento da banda típica de estiramento $\mathrm{CN}$ em $2272 \mathrm{~cm}^{-1}$ durante o intervalo de tempo para uma reação envolvendo o acetato de celulose e o TMI.

A frequência de vibração da banda de $\mathrm{CN}$ do isocianato se situa em uma posição do espectro que é estratégica visto que nesta região não ocorre interferência de qualquer outra banda. $\mathrm{O}$ tratamento cinético da reação entre os grupos isocianatos e grupos hidroxílicos da celulose é realizado por intermédio da quantificação das áreas das bandas dentro dos respectivos intervalos de tempo das reações.

\section{Descrição do Tratamento Cinético e Determina- ção da Constante de Velocidade}

As reações entre os grupos hidroxílicos celulósicos e os isocianatos empregados nesse trabalho seguem uma cinética de segunda ordem, com equação descrita abaixo:

$$
\frac{A_{0}-A_{t}}{A_{0}}=k C_{0} t
$$

Onde:

$\mathrm{A}_{0}$ representa a absorção da banda de estiramento $\mathrm{CN}$ ao tempo zero;

$\mathrm{A}_{t}$ representa a absorção da banda de $\mathrm{CN}$ ao tempo t;

$\mathrm{C}_{0}$ representa a concentração inicial de isocianato.

A equação (1) acima pode ser aplicada para o caso específico onde as concentrações dos reagentes são as mesmas. Logicamente esse caso é particular, o que faz necessário o desenvolvimento de uma equação mais ampla que descreva um processo cinético onde as concentrações não sejam exatamente as mesmas.

Se:
$[\mathrm{OH}]_{0}=\mathrm{b}$
$[\mathrm{NCO}]_{0}=\mathrm{a}$
$[\mathrm{OH}]_{\mathrm{t}}=\mathrm{b}-\mathrm{x}$
$[\mathrm{NCO}]_{\mathrm{t}}=\mathrm{a}-\mathrm{x}$

A solução da equação diferencial segue:

$$
\left[\ln \left(\frac{b-x}{a-x}\right)\right]-\ln \frac{b}{a}=k(b-a) t
$$


As equações (1) e (2) apresentadas são clássicas e perfeitamente empregadas para processos cinéticos de segunda ordem respeitando-se taxas de conversões de até 70-80\% ${ }^{[9]}$. Acima desse valor podem ser observados desvios positivos ou negativos que aparecem como retas, também de segunda ordem e com inclinações que diferem da reta inicial ${ }^{[10]}$. Esse fenômeno tem sido constantemente observado e existem muitas controvérsias na literatura para explicar tais desvios $^{[10]}$. Em uma das teorias mais aceitas, os desvios positivos são explicados pelo fenômeno de autocatálise provocado pela própria uretana formada durante a reação. Outra hipótese também descrita é a existência de um consumo de grupos $\mathrm{NCO}$ em reações secundárias que a princípio levariam à formação de alofanatos ${ }^{[10,11]}$.

A Figura 4 mostra o acompanhamento cinético para as reações equimolares de acetato de celulose com IEM e acetato de celulose com TMI.

A figura mostra a boa linearidade das curvas cinéticas de segunda ordem obtidas para as reações entre o acetato de celulose e os respectivos isocianatos. Observa-se ainda a ocorrência de desvios positivos a partir de taxas de conversão superiores a $75 \%$ para a reação com o IEM o que pode indicar a ocorrência do fenômeno de autocatálise, como citado anteriormente.

Uma comparação entre os dois sistemas reacionais mostra que a reação entre acetato de celulose e $T M I$ é mais lenta quando comparada à reação com IEM (constantes de velocidade iguais a $3,1 \times 10^{-3}$ L. $\mathrm{mol}^{-1} \cdot \mathrm{min}^{-1}$ e $1,1 \times 10^{-2} \mathrm{~L} \cdot \mathrm{mol}^{-1} \cdot \mathrm{min}^{-1}$ respectivamente). Considerando-se que ambos isocianatos são ligados a cadeias alifáticas.A explicação mais lógica para a baixa reatividade do TMI é o impedimento estérico causado pelos dois grupamentos metilas pre-

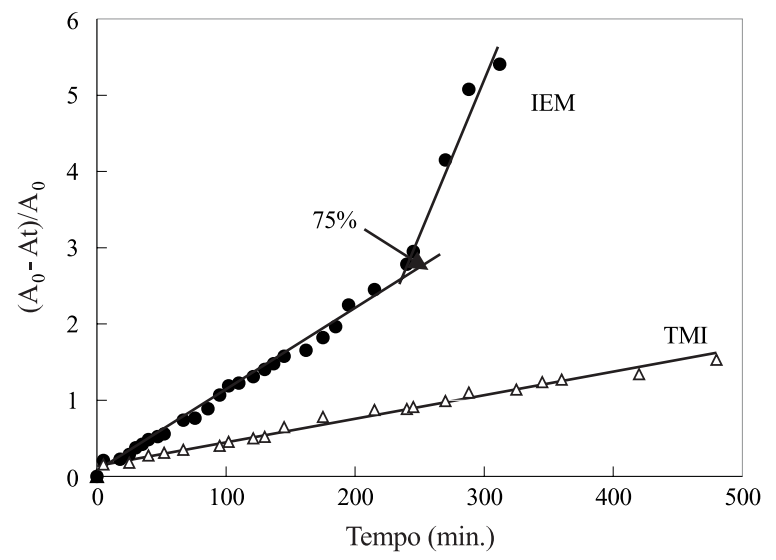

Figura 4. Acompanhamentos cinéticos das reações entre acetato de celulose e os isocianatos.
Tabela 2. Constantes de velocidade $\left(\mathrm{k}, \mathrm{L} \cdot \mathrm{mol}^{-1} \cdot \mathrm{min}^{-1}\right)$ para as reaçõespadrão envolvendo os isocianatos, água e metanol.

\begin{tabular}{ccc}
\hline Reação & $\begin{array}{c}\mathbf{k} \\
\left(\mathbf{L} \cdot \mathbf{m o l}^{-1} \cdot \mathbf{m i n}^{-1}\right)\end{array}$ & $\begin{array}{c}\text { Fator de } \\
\text { correlação das } \\
\text { equações } \\
\text { cinéticas obtidas }\end{array}$ \\
\hline Metanol/TMI & $4,34 \times 10^{-2}$ & 0,999 \\
Metanol/IEM & $8,53 \times 10^{-1}$ & 0,994 \\
Água/TMI & $5,57 \times 10^{-3}$ & 0,997 \\
Água/IEM & $1,564 \times 10^{-1}$ & 0,998 \\
\hline
\end{tabular}

sentes no carbono ligado à função isocianato. Essa menor reatividade do $T M I$ também foi observada para as reações entre os isocianatos com água ou metanol, como indicado pelos valores das constantes de velocidade da Tabela 2.

Os dados da tabela mostraram que para ambos os casos analisados nas reações com água e reações com metanol, o TMI é menos reativo que o IEM como observado anteriormente para o caso das reações com $\mathrm{o}$ acetato de celulose. Finalmente os excelentes fatores de correlação obtidos mostraram a confiabilidade do método empregado na determinação das constantes de velocidade.

Caracterização dos filmes por espectrosocopia na região do infravermelho com transformada de Fourier (FTIR)

As Figuras 5 e 6 mostram os espectros de FTIR obtidos para os filmes de acetato de celulose original, filmes modificados com TMI e IEM e respectivos isocianatos.

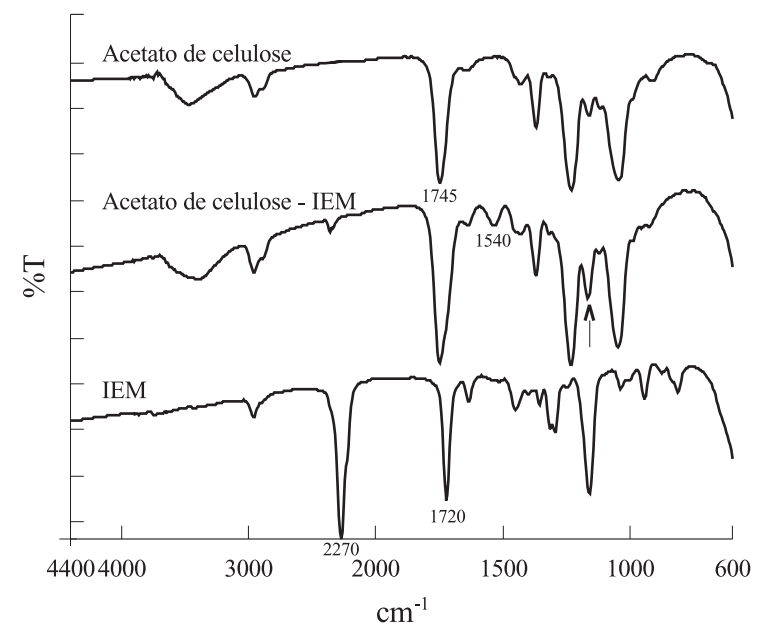

Figura 5. Espectros de FTIR para o IEM, filme de acetato de celulose e filme modificado. 


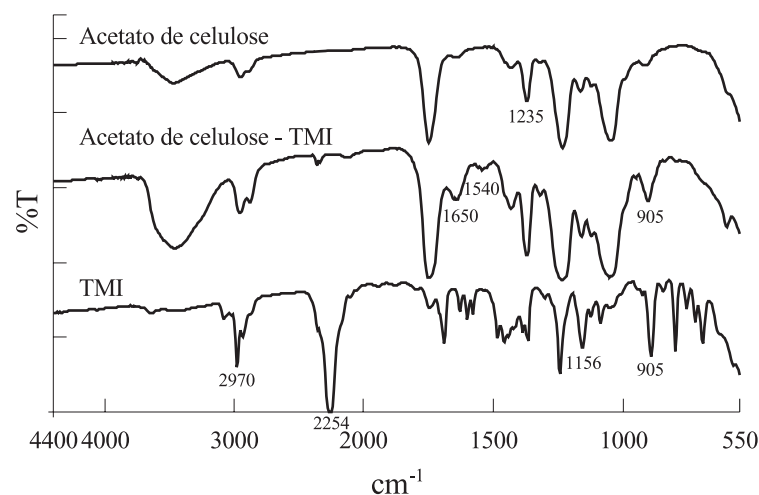

Figura 6. Espectros de FTIR para o TMI, filme de acetato de celulose e filme modificado.

Uma comparação entre os espectros das figuras 5 e 6 mostra a presença de uma banda de absorção em $1540 \mathrm{~cm}^{-1}$ que aparece de forma clara nos filmes modificados e é completamente ausente no espectro do acetato de celulose original. Essa banda já foi observada na literatura para filmes de acetato de celulose modificados com diisocianatos e é atribuída à segunda banda de absorção da carbonila do grupo uretana ${ }^{[12]}$.

Outras bandas importantes que fornecem boas informações comparativas são as bandas da região das carbonilas. Para o caso dos espectros do acetato não modificado, do IEM e do TMI, essas bandas são estreitas e aparecem 1745, 1720 e $1715 \mathrm{~cm}^{-1}$ respectivamente como esperado para esses compostos. Por outro lado a banda de carbonila presente no espectro do filme modificado com IEM é mais larga, sugerindo a ocorrência de superposição entre as bandas de carbonila do acetato de celulose e do isocianato. Finalmente pode-se observar a banda mais pronunciada C-O-C do acrilato ao redor de $1150 \mathrm{~cm}^{-1}$ no espectro do filme modificado com IEM.

Tabela 3. Resultados obtidos para as medidas de ângulos de contato de gotas d'água depositadas sobre as superfícies dos filmes de acetato de celulose e filmes modificados.

\begin{tabular}{cccc}
\hline Filme & $\begin{array}{c}\text { Ângulo de } \\
\text { Contato }\left({ }^{\circ}\right) \\
\text { (Valores Médios) }\end{array}$ & Filme & $\begin{array}{c}\text { Ângulo de } \\
\text { Contato }\left({ }^{\circ}\right) \\
\text { (Valores Médios) }\end{array}$ \\
\hline $\begin{array}{c}\text { Acetato de } \\
\text { Celulose }\end{array}$ & 0 & & \\
TMI125 & 85 & IEM125 & 40 \\
TMI225 & 87 & IEM225 & 42 \\
TMI325 & 89 & IEM325 & 65 \\
TMI425 & 91 & IEM425 & 66 \\
\hline
\end{tabular}

O aparecimento da banda em $905 \mathrm{~cm}^{-1}$ no espectro do acetato de celulose modificado com TMI é particularmente importante nesse caso pois é uma consequência da introdução de anéis aromáticos meta-substituídos na estrutura do acetato modificado. Deve-se também observar que essa banda está presente no espectro de infravermelho do reagente puro. Outra modificação importante é o alargamento da banda a $3340 \mathrm{~cm}^{-1}$ que é uma consequência da aparição de grupamentos N-H no filme de celulose modificado. Pode-se observar novamente a superposição de bandas de carbonila em torno de $1740 \mathrm{~cm}^{-1}$ no filme modificado com TMI.

\section{Determinação de ângulos de contato}

A Tabela 3 mostra os valores médios obtidos para os ângulos de contato de gotas d'água depositadas sobre os filmes de acetato de celulose e sobre os filmes modificados.

Os resultados mostram que em todos os casos analisados, os valores de ângulo de contato obtidos para os filmes modificados são superiores ao valor obtido para o acetato de celulose original. Esse resultado indica a ocorrência de modificação e mostra que as superfícies dos filmes modificados são mais hidrofóbicas que o acetato de celulose original. Essa maior hidrofobia é uma consequência da introdução de estruturas pouco polares nas superfície dos filmes modificados. O aumento da concentração de isocianato levou à superfícies mais modificadas e mais hidrofóbicas, como mostrado pelo aumento dos valores de ângulo de contato obtidos tanto para os filmes modificados com TMI quanto com IEM. Finalmente o maior carater hidrofóbico do TMI, que possui um anel aromático na sua estrutura, explica os valores de ângulos de contato superiores para os filmes modificados com TMI quando comparados aos filmes modificados com IEM.

O ensaio da gota d'água sob o filme de acetato de celulose original foi seguido por um tempo de aproximadamente 10 minutos e pode-se mesmo observar a total penetração da gota sobre a superfície, resultando em um valor de zero para o ângulo de contato . Por outro lado, não foi observada variação significativa dos ângulos obtidos para os filmes modificados no mesmo intervalo de tempo. A figura 7 mostra a queda inicial rápida do ângulo de contato da gota d'água sobre o filme de acetato não modificado e a estabilidade da gota sobre os filmes modificados com os isocianatos.(Tabela 3) 


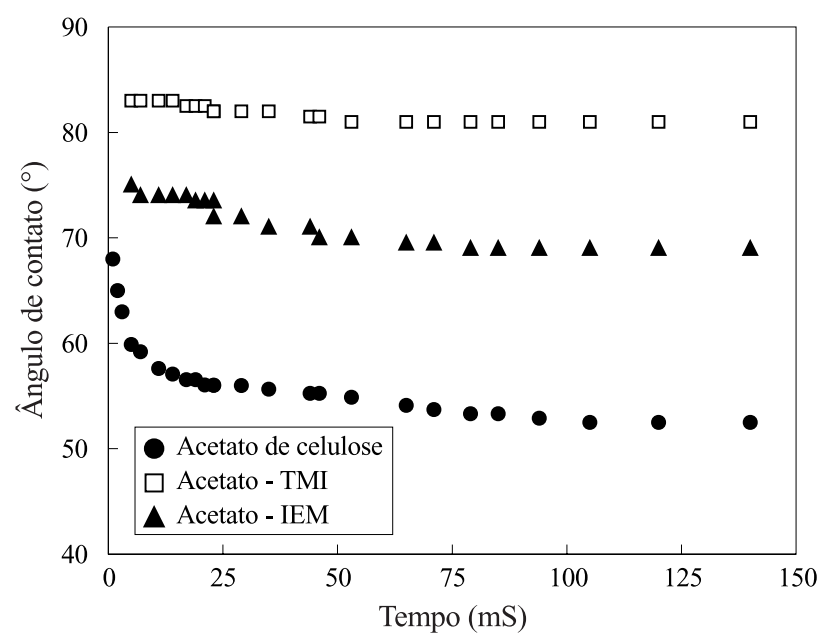

Figura 7. Variação do ângulo de contato com o tempo para os filmes de acetato de celulose e para os filmes modificados com isocianatos.

\section{Análises de Tração}

Os ensaios de tração foram realizados de forma comparativa entre o filme de acetato de celulose e os filmes modificados e sob condições experimentais controladas para todos os casos. Os principais parâmetros experimentais controlados foram as dimensões dos filmes, umidade relativa, temperatura e velocidade de tração.

Os ensaios de tração foram realizados no mínimo oito vezes para cada filme sendo que a tabela 4 mostra os valores médios experimentais obtidos para a carga máxima de ruptura e o módulo de Young.

Os dados da Tabela 4 mostram que em todos os casos analisados os filmes modificados apresentaram valores de resistência à tração e módulo de Young inferiores aos valores obtidos para o filme de acetato de celulose original. Deve-se destacar que quando comparado ao filme original, os filmes modificados apresentam uma diminuição da extensão de ligações por ponte de hidrogênio entre os grupos hidroxílicos do acetato de celulose. Essa diminuição leva a uma maior facilidade de deslocamento das cadeias o que está as- sociado a uma menor resistência à tração. De forma complementar, a modificação com os isocianatos provoca uma diminuição das correspondentes energias coesivas entre macromoléculas que constituem os filmes modificados. Observa-se ainda que para as duas séries estudadas, o aumento da concentração de isocianato levou à obtenção de filmes menos resistentes à tração, o que está associado a um aumento da extensão de substituição dos grupos hidroxílicos.

\section{Conclusões}

O presente trabalho mostrou a viabilidade da modificação do acetato de celulose com dois isocianatos estruturalmente diferentes. De forma geral, todas as técnicas de caracterização empregadas mostraram a ocorrência de modificação da estrutura do acetato de celulose após reação com os grupos $N C O$. Foi possível, por exemplo, comprovar o aumento do caráter hidrofóbico dos filmes modificados quando comparados ao acetato de celulose não modificado. Após modificação, todos os filmes obtidos foram menos resistentes à tração e esse comportamento foi associado a diminuição da extensão de pontes hidrogênio entre os grupos hidroxílicos nos filmes modificados. Uma segunda parte dos trabalhos está em andamento e tem como objetivo o aproveitamento das duplas ligações (estirênicas ou acrílicas) presentes na estrutura do acetato de celulose modificado. Essas duplas ligações podem participar de processos de polimerização com monômeros como o estireno e o metacrilato de metila com a finalidade de se obter celuloses modificadas com estruturas poliméricas sintéticas.

\section{Agradecimentos}

O Dr. Vagner Roberto Botaro agradece a FAPESP - Fundação de Amparo a pesquisa do Estado de São Paulo - pela bolsa de pós-doutorado concedida e a

Tabela 4. Valores de carga máxima de ruptura $(\mathrm{N})$ e módulo de Young $\left(\mathrm{kg} / \mathrm{m}^{2}\right)$ obtidos para os ensaios de tração dos filmes de acetato de celulose e filmes modificados.

\begin{tabular}{cccccc}
\hline Amostra & $\begin{array}{c}\text { Carga de } \\
\text { Ruptura (N) }\end{array}$ & $\begin{array}{c}\text { Módulo } \\
\left(\mathbf{k g . m}^{-2}\right) \mathbf{x 1 0}\end{array}$ & Amostra & $\begin{array}{c}\text { Carga de } \\
\text { Ruptura (N) }\end{array}$ & $\begin{array}{c}\text { Módulo } \\
\left(\mathbf{k g} \cdot \mathbf{m}^{-2}\right) \mathbf{x 1 0}\end{array}$ \\
\hline Acetato & 49,5 & 2,30 & Acetato & 49,5 & 2,30 \\
TMI125 & 44,5 & 2,03 & IEM125 & 33,1 & 1,25 \\
TMI225 & 39,0 & 1,46 & IEM225 & 29,8 & 0,88 \\
TMI325 & 34,0 & 1,30 & IEM325 & 23,9 & 0,49 \\
TMI425 & 29,0 & 1,30 & IEM425 & 14,6 & 0,14 \\
\hline
\end{tabular}


EFPG/Grupos de Materiais Poliméricos - Grenoble, França, pelo apoio técnico e financeiro.

\section{Referências Bibliográficas}

1. Fengel, D.; Wegner, G.- "Wood Chemistry, Ultrastructure and Reactions"; Walter de Gruyter, Berlin/New York (1984).

2. Gandini, A.- "Comprehensive Polymer Science"; Pergamon Press, Oxford, 527-573 (1992).

3. Hon, D. N-S.- "Chemical Modification of Lignocellulosic Materials", Marcel Dekker Inc., New York/Basel/Hong-Kong (1996).

4. Hon, D. N-S.; Shiraishi, N.- "Wood and Cellulosic Chemistry" - Marcel Dekker Inc - New York/ Basel (1991).

5. Gandini, A.; Belgacem, M.N.- Polymeric materials Encyclopedia - Salamone, J. C. Eds.; CRC Press, New York, 11, 8518-8541 (1996).
6. Trejo-O'Reilly, J. A.; Cavaillé, J. Y.; Gandini, A.Polymer Bulletin 34, 265-270 (1995).

7. Botaro, V. R.; Gandini, A.; Trabalho aceito Cellulose 000.

8. Aurenty, P., Lanet, V., Tessadro, A. and Gandini, A.- Rev. Sci. Instrum, 68, 1801-1808 (1997).

9. Belgacem, M. N.; Quillerou, J.; Gandini, A.- Eur. Polym. J., 29, 1217-1224 (1993).

10. Belgacem, M. N.; Sami, B.; Quillerou, J.; Gandini, A.- Macromolecules, 2, 6706-6717 (1993).

11. Pielichowski, J;; Atamanczuk, B.- J. Appl. Polym. Sci., 46, 2139-2146 (1992).

12.. Hsieh, K. H.; Lin, B.Y.; Chiu, W. Y.Desalination, 71 - Elsevier S. C. Publ. - B. V., 97-105 (1989).

Recebido: $21 / 11 / 97$

Aprovado: 06/04/98 